\title{
Application of Wavelet Transform for Fault Diagnosis in Swash Plate Pump's Control Unit Causing Pipes Flutter
}

\author{
Molham Chikhalsouk and Rama B. Bhat
}

\begin{abstract}
Vibration analysis is fundamental in enhancing condition monitoring and fault diagnostics of control unit in swash plate pumps. Several signal analysis methods are used to obtain useful information from vibration signatures. Presently, the most of these methods use spectral analysis based on Fourier Transform (FT). However, these methods exhibit some limitations; it is the case of transient signals when the irregularity is the pattern. In the present paper, we are interested to apply Discrete Wavelet Analysis (DWA) to the vibration signal analysis. The DWT is one of the most promising methods for signal processing; it is especially convenient for transient vibration measurements obtained from accelerometer sensors. The monitoring results indicate that the DWT can diagnose the abnormal change in the measured data.
\end{abstract}

Index Terms-Vibration analysis, fault diagnosis, control unit, swash plate pumps, spectral analysis, wavelet transforms.

\section{INTRODUCTION}

The increasing demand for excellent performance, safety and reliability of industrial systems has increased the demand for fault diagnosis. Fault diagnosis has been becoming much more important in process monitoring. In the past 20 years, huge breakthrough in sensors, which are employed successfully in condition monitoring and fault diagnosis, such as; vibration displacement, dynamic force, noise levels, temperature, etc. The vibration signature analysis today is one of the most effective methods used in condition monitoring and fault diagnostics, where they always obtain the dynamic information of the system. In order to extract useful information from the vibration signals, it is very critical to apply convenient signal processing techniques for the specific fault diagnostics. With the rapid development of the signal processing techniques, the analysis of stationary signals has largely been based on well-known spectral techniques such as: Fourier Transform (FT), Fast Fourier Transform (FFT) and Short Time Fourier Transform (STFT) [1], [2]. Unfortunately, the methods based on FT are not suitable for non-stationary signal analysis [3]. In addition, they are not able to reveal the inherent information of non-stationary signals. These methods provide only a limited performance for machinery diagnostics [4]. In order to solve these problems, Wavelet Transform (WT) has been developed. WT is a kind of variable window technology, which uses a time interval to analyze the high frequency and the low frequency components of the signal [5], [6]. The data using WT can be decomposed into approximation and detail

Manuscript received October 9, 2014; revised May 4, 2015.

The authors are with the Concordia University, Department of Mechanical and Industrial Engineering, 1455 de Maisonneuve Blvd. West, Montreal, Quebec, H3G 1M8, Canada (e-mail: chikhalsouk@yahoo.com, rbhat@vax2.concordia.ca). coefficients in a multi-scale, presenting then a more effective tool for non-stationary signal analysis than the FT. Many studies present the applications of WT to decompose signals for improving the performance of fault detection and diagnosis in rotating machinery [7], [8]. In this work, we propose to implement the WT for condition monitoring of swash plate pump. It is evaluated using the experimental measurements data in the cases of accurate and appropriate control unit gains. The main goal of this technique is to obtain more detailed information contained in the measured data. The remainder of this paper is organized as follows. Section II presents WT method and its formulations. Section III presents the importance and structure of Swash Plate Pumps. Problem statements and faults descriptions are presented in Section IV. The monitoring results are discussed in Section VI. Finally, Section VII concludes our contributions.

\section{WAVELET TRANSFORM}

The last two decades witnessed an extensive progress in Wavelet Analysis. Wavelets have appealed to scientists and engineers of many different backgrounds. WT has led to exciting applications in signal analysis and numerical analysis, and many others applications are being studied [9], [10].

DWT is considered a powerful tool to detect the changes of a signal. DWT is translated and scaled in discrete steps. It is a piecewise continuous function and can be given as:

$$
W(a, b)=\frac{1}{\sqrt{a}} \sum_{n} \sum f(n) \varphi\left(\frac{n-b}{a}\right)
$$

Eq. (1) represents a discrete wavelet transform, where " $a$ " is a scale function, $\varphi\left(\frac{n-b}{a}\right)$ is the mother wavelet or wavelet basis, $\mathrm{n}$ is an integer number, and " $b$ " is a dilation indicating number. The parameter $\frac{1}{\sqrt{a}}$ is introduced in order to normalize the mother wavelet to have unit energy at every scale. To solve this equation, the parameters " $a$ " and " $b$ " should be determined.

For a dyadic discrete sampling, " $a$ " can be expressed as

$$
a=2^{j}
$$

where " $j$ " is the number of decompression levels, while " $b$ " can be expressed as :

$$
b=2^{j} \cdot k
$$

where $k$ is an integer, $t$ is time, $f(t)$ is the signal, and $n$ is the number of samples. The scale, $a$, is inversely proportional to 
the frequency. $W(a, b)$ can be represented as either frequency-time or scale-time representation. In most of the previous works, the $W(a, b)$ representation is in scale-time representation. The reason is that there is no exact relationship between scale and the frequency.

In [11], Mallat suggested that multi-resolution analysis is needed to obtain the DWT of a discrete signal by implementing low and high pass filters, and then down sampling them by two as is illustrated in Fig. 1-Fig. 2 and described below. It employs two sets of functions, called scaling functions and wavelet functions [12], [13], which are associated with low and high pass filters, respectively. The discrete signal is passed through a high pass filter $(\mathrm{H})$ and a low pass filter $(\mathrm{g})$, resulting in two vectors at the first level; approximation coefficient $\left(\mathrm{A}_{1}\right)$ and detail coefficient $\left(\mathrm{D}_{1}\right)$ [14], [15]. Application of the same transform on the approximation $\left(\mathrm{A}_{1}\right)$ causes it to be decomposed further into approximation $\left(A_{2}\right)$ and detail $\left(D_{2}\right)$ coefficients at the second level. Finally, the signal is decomposed at the expected level. The approximations are the high-scale, low-frequency components and the details are the low-scale, high-frequency components of the signal.

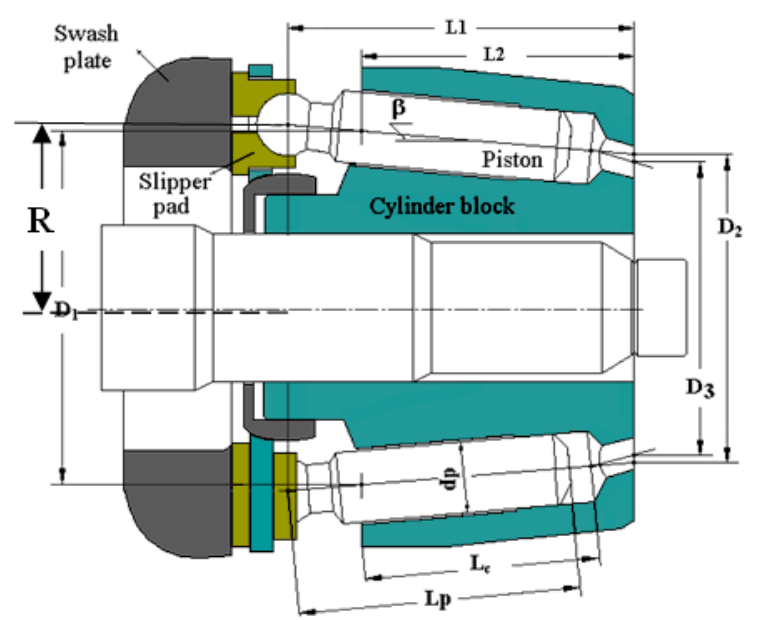

Fig. 1. Main components of a swash plate pump with a cylindrical arrangement.

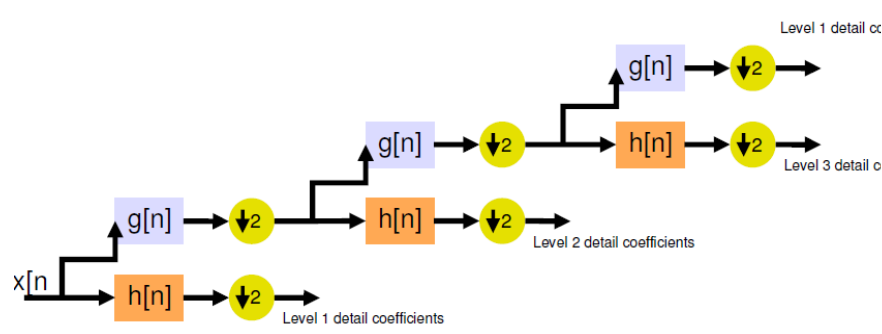

Fig. 2. Computation of DWT by multi resolution analysis (filters bank).

\section{SWASh Plate PUMPS}

Swash plate pumps are widely used in hydraulic systems to provide pressure/flow for a range of equipment in engineering applications. With a constant prime mover speed, the delivery flow-rate is changed by controlling the swash plate angle i.e. the inclination angle, and hence delivery pressure can be controlled. Ideally, the pump delivery pressure needs to match the system load pressure. In this aspect, several control disciplines applied to improve electro-hydraulically pressure controlled pump systems, among which mostly linear control methods are employed (Akers and Lin, [16]; Lanitto, and Johnson, [17]; Akers and Lin [18]). Using a proportional solenoid valve to control flow for adjusting the inclination angle, a nonlinear control strategy has been developed for pump delivery pressure control which is capable of on-line adaptive compensating for the change of the pressure carry over angle (Manring,[19]-[22]).

As shown in Fig. 2, the swash plate pump contains of finite number of pistons within a common cylindrical block. The pistons are nested in a circular array within the block at equal intervals about the shaft axis. The cylinder block is held firmly against a port plate using the force of the compressed cylinder-block spring. A ball-and-socket joint connects the base of each piston to a slipper. The slippers themselves are kept in contact with the swash plate and the swash plate inclination angle is controlled by a servomechanism based upon the requirements of the delivery pressure and/or delivery flow rate. For practical applications, the loads on any hydraulic actuator can change from time to time, which in turn requires the hydraulic pump to provide a different operating pressure accordingly.

\section{Problem Statement}

In the earlier pump designs, the pump was operated without control units, operating at a certain flow regardless of the desired flow. In order to manage the excess flow, a relief valve was used. The valve solved the excessive flow problem; however, a fluid overheating was encountered. The fluid overheating deteriorates its properties and damages the pump parts. The loss of the pump power and the overheating were major challenges that designers encountered and a control system is needed to solve these problems.

The later design equipped the pump with a double negative control unit to control both valve spool and swash plate angle a control unit to control the power according to load requirements by controlling the swash plate swiveling. Hence, the pump power matches completely the load, and the oil maintains its healthy condition. This solution is expensive, as more parts are needed, and lead to slow response. In [23], a single feedback loop to control the pump was proposed, and they compared that control strategy with several other control strategies. Their objective was to simplify the control scheme and the associated electronics, which reduces the pump's production cost.

However, pump smoothness performance on the piping system was not investigated, which is considered as faulty components in hydraulic systems.

In the coming sub-item, the control unit components, the pump mathematical model, and the single feedback control schematic representation will be explained.

\section{A. Control Unit Components}

The control unit has the following components: the secondary power pump, the hydraulic proportional valve, and the electronic control unit. A pressure transducer senses the load pressure and feeds it to the logic unit of the control unit. The logic unit calculates the required swash plate swiveling 
angle that matches the load demands without exceeding the pump manufacturer specifications such as: its power, maximum flow, and maximum pressure. The control unit components of are illustrated in Fig. 3.

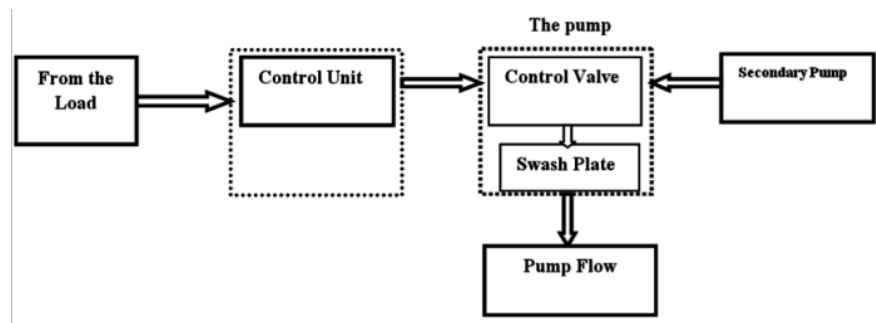

Fig. 3. A schematic representation for the control unit/pumps, and the hydraulic and electrical flows.

\section{B. Pump Mathematical Model}

The swash plate is modeled as a single degree-of-freedom system (SDOF) with respect of the swiveling angle of the swash plate about the $y$ axis i.e. $\varphi$. The swash plate contributes the inertial mass, which can be expressed as $J_{e q}$. Moreover, such the hydraulic piston restoring spring and its damper coefficients are $K_{e q}, C_{e q}$, respectively.

The equation of motion is expressed as:

$$
J_{e q} \ddot{\varphi}+C_{e q} \dot{\varphi}+K_{e q} \varphi=M(t)
$$

where

$J e q=$ total equivalent inertial moment for the swash plate

$C e q=$ hydraulic piston total equivalent damping

$\ddot{\varphi}=$ swiveling angle second derivative (angular acceleration)

$\dot{\varphi}=$ derivative of the swiveling angles (angular velocity)

$\varphi=$ swiveling angles (angular displacement)

$M=$ Applied moment on the swash plate

$K_{e q}=$ hydraulic piston total equivalent restoring spring stiffness

The transfer function for the swash plate can be expressed in S- domain as

$$
T=\frac{\varphi(s)}{M(s)}=\frac{\omega_{n}^{2}}{s^{2}+2 \varsigma \omega_{n} s+\omega_{n}^{2}}
$$

where

$\omega_{n}=$ Natural frequency $\mathrm{rad} / \mathrm{sec}$

$\zeta=$ Damping ratio

$S=$ Laplace variable

Values of $\omega_{n}$ and $\zeta$ are calculated in the appendix

Selecting the right parameters for the controller i.e. the right controller gains, determines the pump overall performance in terms of pump load responsiveness and smoothness, which are dominant in superior pump performance are the top priority of the pump designers and manufacturers.

The control is a single feedback, as explained earlier. Accordingly, the two conditions to be studied:

1) Faulty pump: When using PD controller $(K p=1$, $K d=0.02, K i=0$ )

2) Healthy pump: When implementing PID controller $(K P=$ 1.9, $K D=0.1 K i=8.4)$.

\section{Faulty Pump (PD Controller): Faulty Pump}

Khalil and Bhat [23] proposed $a$ new control strategy to control the pump output by implementing a single feedback loop. They removed the electrical feedback line of the inner loop for the spool and controls only pump swiveling angle (Fig. 4).

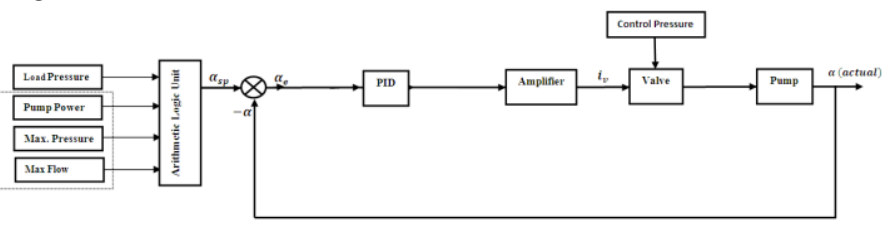

Fig. 4. Swash plate pump with single feedback control loop representation (PID controller).

Then they parameterized the PD controller by using Ultimate Sensitivity method. The parameters of the PID controller were $K P=1, K i=0$, and $K D=0.02$. The model was validated experimentally; however, the vibration levels on the system components were not evaluated.

In the present work, the authors proposed a healthy pump to be equipped with a convenient PID controller. The criteria of healthy pump from control system perspective when it has a rapid response and smooth operation. The comparison between the two pumps is summarized in Table I-Table II.

TABLE I: COMPARISON BETWEEN HEALTH PUMP AND FAULTY PUMPS PERFORMANCE

\begin{tabular}{|l|l|l|}
\hline & $\begin{array}{l}\text { Healthy Pump } \\
\text { (PID) }\end{array}$ & Faulty Pump (PD) \\
\hline$K p$ & 1.9 & 1 \\
\hline$K I$ & 8.4 & 0 \\
\hline$K d$ & 0.1 & 0.02 \\
\hline Rise Time (ms) & 15 & 60 \\
\hline Vibration Max (mm) & \pm 0.05 & \pm 0.5 \\
\hline $\begin{array}{l}\text { Vibration } \\
\text { Reduction \% }\end{array}$ & 90 & 0 \\
\hline
\end{tabular}

\begin{tabular}{|c|c|c|c|}
\hline Symbol & Description & Value & Unit \\
\hline$A_{c p}$ & Area of the control piston & $8.1 \times 10-4$ & $\mathrm{~m}^{2}$ \\
\hline$A_{p}$ & Piston cross-section area. & $2.27 \times 10-4$ & $\mathrm{~m}^{2}$ \\
\hline$B$ & Effective bulk modulus & $1 \times 109$ & $\mathrm{~Pa}$ \\
\hline$C_{d}$ & Coefficient of discharge. & 0.611 & - \\
\hline$D_{1} / R_{1}$ & $\begin{array}{l}\text { Pitch circle } \\
\text { diameter/radius of the } \\
\text { cylinders' arrangement at } \\
\text { the base of the cylinder } \\
\text { block }\end{array}$ & $0.07175 / 0.0359$ & $\mathrm{~m}$ \\
\hline$D_{2} / R_{2}$ & $\begin{array}{l}\text { Pitch circle } \\
\text { diameter/radius of the } \\
\text { cylinders' arrangement at } \\
\text { the top of the cylinder } \\
\text { block }\end{array}$ & $0.0602 / 0.0301$ & $\mathrm{~m}$ \\
\hline$f_{v}$ & $\begin{array}{l}\text { Control valve equivalent } \\
\text { viscous friction } \\
\text { coefficient }\end{array}$ & 90 & N.s/m \\
\hline$f_{\alpha}$ & $\begin{array}{l}\text { Equivalent angular } \\
\text { viscous friction } \\
\text { coefficient of the swash } \\
\text { plate }\end{array}$ & 1.5 & $\mathrm{Nm} /(\mathrm{rad} / \mathrm{s})$ \\
\hline$I_{e}$ & $\begin{array}{l}\text { Equivalent moment of } \\
\text { inertia of the swash plate }\end{array}$ & .0039 & kg. $\mathrm{m}^{2}$ \\
\hline$k_{i}$ & $\begin{array}{l}\text { Proportional solenoid } \\
\text { force-current constant }\end{array}$ & 2.5 & N/A \\
\hline
\end{tabular}

TABLE II: PUMP KEY PARAMETERS AND DIMENSIONS

\section{EXPERIMENTAL SETUP}

In order to record the pipe vibration signature, a piezoelectric accelerometer is placed at the midpoint of the 
pipe and on the pump discharge pipe (illustrated in Fig. 5) The recorded signal is simultaneously fed to amplifier-filter to improve the quality of the recorded signal and to reduce the noise. To convert the analog signal into digital signal, software based on LABVIEW ${ }^{\circledR}$ is used to acquire the data. The model of the data acquisition card is DAQ $6062 \mathrm{E}$ (from National Instruments Inc.). The schematic representation is illustrated in Fig. 6. To obtain reliable results, the sampling time is selected to be $5 \mathrm{~m} \mathrm{sec}$. and the total number of the collected number of the recorded data for each experiment run is 2000 points. The number of points is enough to cover and characterize the final shape of the signal (more than one motor cycle can be covered at every experiment run). After filtering the signals, they are passed through oscilloscope (Agilent - 54624 A) and then recorded. MATLAB ${ }^{\circledR}$ wavelet toolbox is used to analyze the recorded signals and map them (time-scale representation). The pump flow rate is $1 \mathrm{~L} / \mathrm{Sec}$, and the fluid velocity through the pipe is $2.94 \mathrm{~m} / \mathrm{sec}$. The fluid velocity is too small to generate pipe flutter (the flutter velocity is $94.5 \mathrm{~m} / \mathrm{sec}$ ).

Two sets of set up are arranged:

1) The pump is equipped with $\mathrm{PD}$ controller (proportional-derivative controller) to simulate the faulty control system i.e. faulty pump. The derivative action amplifies noise if it exists (noise always has a small amplitude and high frequency). The physical electrical control system is replaced by real time control software to help in the prototyping of the control scheme.

2) The pump is equipped with PID controller with convenient tuned gains. This is the healthy pump that can be validated experimentally based on pipe vibration level and the pump responsiveness i.e. the rise time.
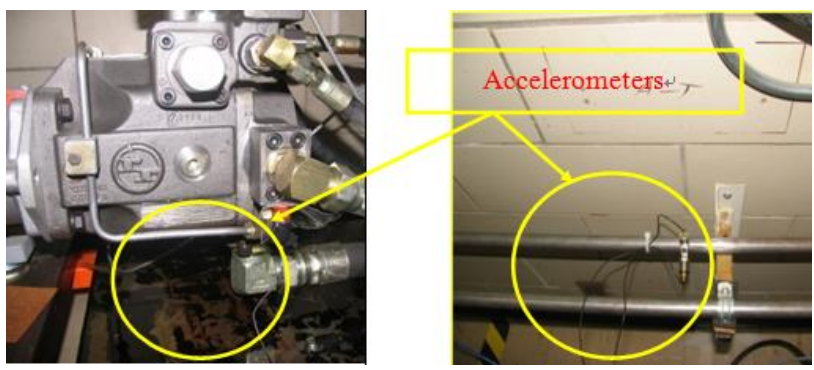

Fig. 5. The location of the accelerometer on the pump outlet and pipe.

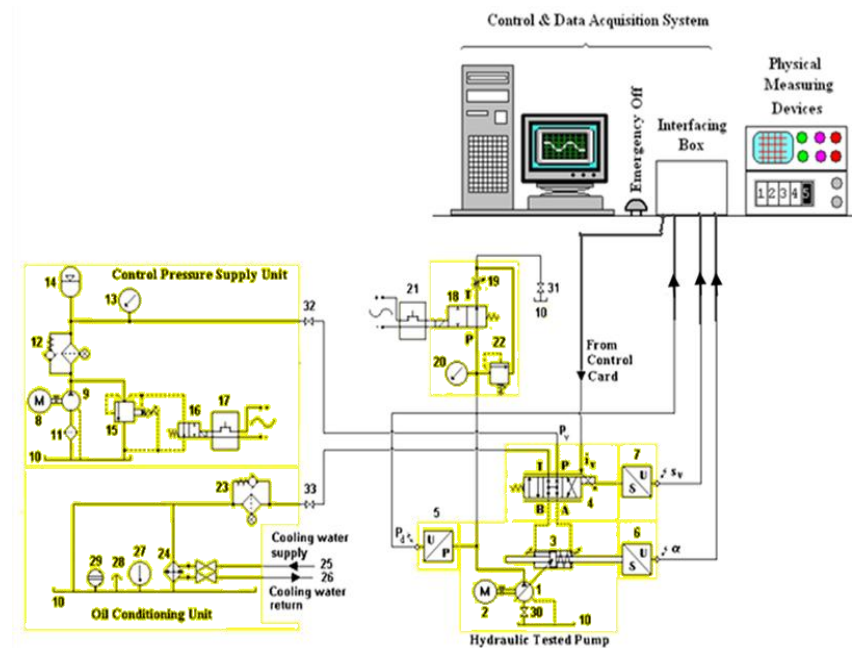

Fig. 6. Experiment setup scheme, including hydraulic and control parts /data acquisition unit.

\section{RESUlts}

The accelerometer readings are recorded for the pipe under two conditions and are plotted as seen in the below figures.

Fig. 7 (the upper figure) shows the pipe vibration signatures under normal operating conditions with PID controller i.e. healthy pump. The vibration amplitude shows regularity and vibrates in the range $\pm 0.05 \mathrm{~mm}$

The pipe vibration signature for the faulty pump equipped with the PD controller is illustrated in Fig. 7 (lower). It can be noticed that the vibration amplitude is high $( \pm 0.5 \mathrm{~mm})$, and exhibits irregularity and random patterns.
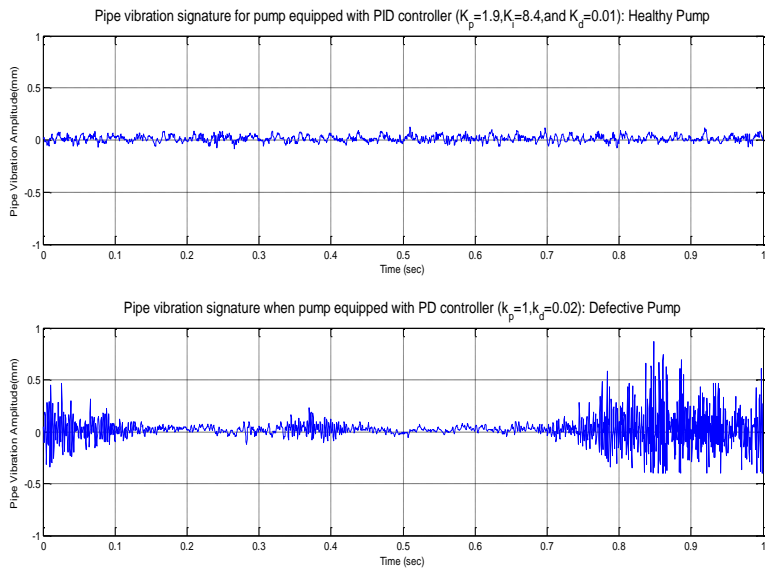

Fig. 7. Pipe vibration signature for the pump equipped with PID controller ( $K_{p}=1.9, K_{i}=8.4$, and $\left.K_{d}=0.01\right)$ and Pipe vibration signature when the pump equipped with $\mathrm{PD}$ controller $\left(k_{p}=1, k_{d}=0.02\right)$.

The coefficients of DWT for the pipe signature under faulty controller operation are illustrated in Fig. 8. The fifth approximate coefficient amplitude is 0.08 ; and it has a minima (equals zero) at $t=900 \mathrm{~m} \mathrm{Sec}$.

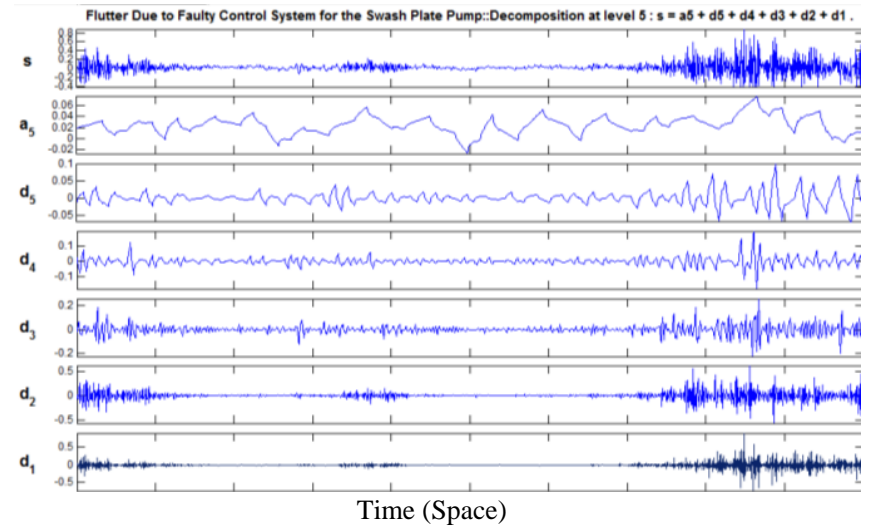

Fig. 8. Time-scale representation of the faulty PD controller i.e. faulty pump.

The coefficients of DWT for the pipe signature under healthy pump operation are illustrated in Fig. 9. The fifth approximate coefficient amplitude is 0.006; and it has a minima (equals zero) at $t=250 \mathrm{~m} \mathrm{Sec.,}$

In order to obtain more details about the two cases, more analysis is done to analyze the signals with two more different techniques: Waterfall diagram to monitor the signal contents evolution for every signal.

Fig. 10 gives more details about the signal in 3D representation. It shows that there is a series of low frequency (about $10 \mathrm{~Hz}$, due to the fluid flow velocity) at the times with 
maximum amplitude equal to $0.033 \mathrm{~mm}$ at $t=950 \mathrm{~m} \mathrm{Sec}$. This irregularity is due to external source or noise.

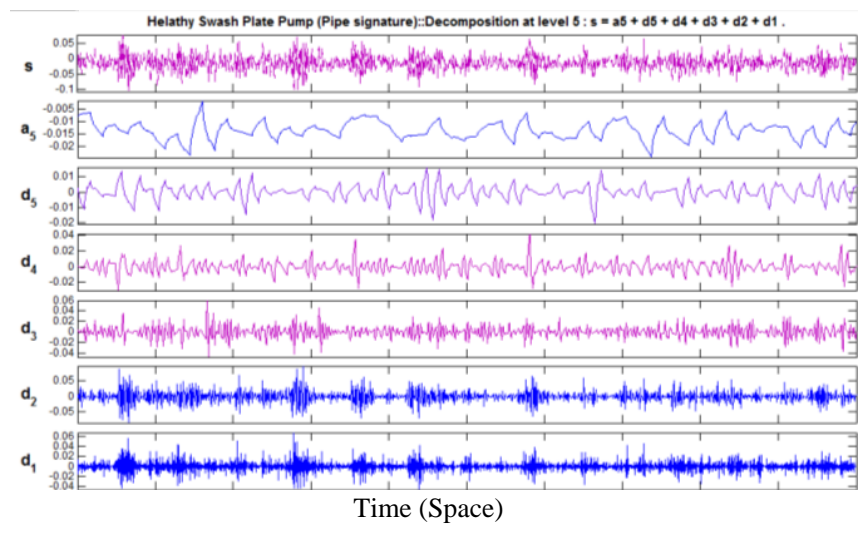

Fig. 9. Time-scale representation of the healthy pump with properly tuned PID controller.

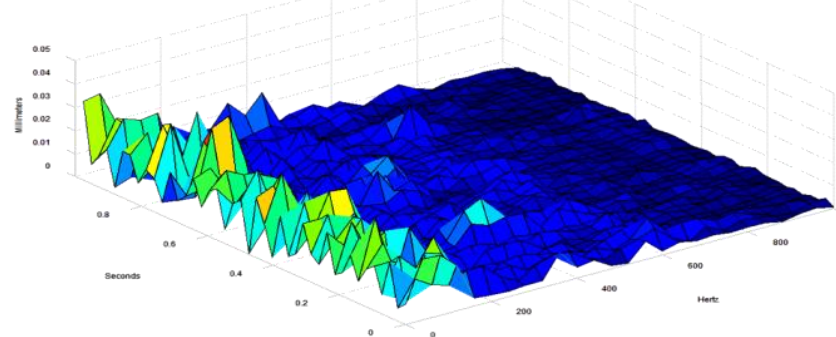

Fig. 10. Waterfall representation of the pipe response with PID controller (normal condition).

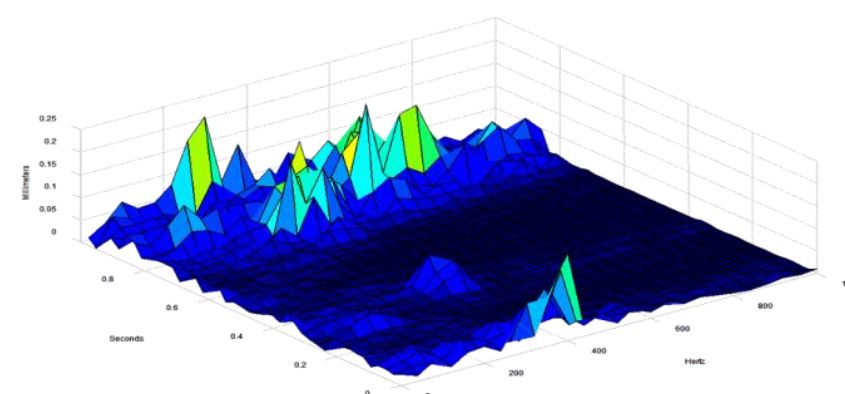

Fig. 11. Waterfall representation of the pipe response with PD controller (flutter condition).

The Waterfall diagram for the pipe signature under flutter is shown in Fig. 11. The vibration amplitude grows with time. This is a symptom of the flutter onset. The high amplitudes are developed starting from $t=900 \mathrm{~m} \mathrm{Sec}$.

The summarized characteristics for normal and faulty/ flutter conditions are:

Normal Operating Condition:

1) The vibration signature varies regularly within the range of $\pm 0.05 \mathrm{~mm}$

2) The DWT maxima is still relatively small 0.006 at $t=250$ msec.

3) A $10 \mathrm{~Hz}$ frequency band can be observed at most times, with amplitude of $0.033 \mathrm{~mm}$.

Faulty Pump Operating Condition:

1) The vibration signature amplifies to reach $( \pm 0.05 \mathrm{~mm})$

2) The fifth approximate coefficient amplitude is 0.08 ; and it has a minima (equals zero) at $t=900 \mathrm{~m} \mathrm{Sec}$.

3) High frequency contents, with the highest energy, can be seen at $t=900 \mathrm{~m} \mathrm{Sec}$.

\section{CONCLUSIONS}

In order to investigate the applicability of wavelet transform in detecting the faulty control systems in swash plate pumps, a set of experiments was carried out. The faulty pump was equipped with a PD controller, which generated dynamic instability in the pump and pipes. The recorded signal of the faulty pump operation condition causing flutter case in addition to the signal of the normal condition were analyzed by using discrete wavelet with Debauches mother wavelet, which is recommended for signals with impulsive vibration signals (the impulse happens due to pressure overshooting of the pump). The wavelet analysis of the two different cases showed two different patterns. For the normal/healthy case, there was regularity in the distribution of the periodicities, while for the faulty/flutter case; there was different pattern and irregularity in the distribution of the periodicities. The periodicities were seen at higher levels (lower frequencies) and they lost the regularity in the temporal distribution. The results show the appropriateness of using wavelet analysis in identifying the defective control unit, which has transient nature.

\section{ACKNOWLEDGEMENT}

The authors would like to thank Dr. Michael Paidoussis from McGill University and Dr. Ali, S.Twareque from Concordia University, Mathematic and Statistics department for their suggestions. Also, we want to extend our gratitude to our technical team, Mr. Dainius Juras, Mr. Gilles Huard, and Mr. Robert Oliver. Also, our great thanks to Mr. Jon Horen from DADISP for his continuous assistance.

\section{REFERENCES}

[1] K. Shibata, A. Takahashi, and T. Shirai, "Fault diagnosis of rotating machinery through visualization of sound signal," Journal of Mechanical Systems and Signal Processing, vol. 14, pp. 229-241, 2000.

[2] G. Strang, "Wavelet transforms versus Fourier transforms," Bulletin of the American Mathematical Society, vol. 28, pp. 288-305, 1993.

[3] J. C. Cexus, "Analyse des signaux non-stationnaires par Transformation de Huang, Opérateur de Teager-Kaiser, et Transformation de Huang-Teager (THT)" Thèse de Doctorat, Université de Rennes-France, 2005.

[4] J. D. Wu and C.-H. Liu, "Investigation of engine fault diagnosis using discrete wavelet transform and neural network," Expert Systems with Applications, vol. 35, pp. 1200-1213, 2008.

[5] S. H. Cao and J. C. Cao, "Forecast of solar irradiance using recurrent neural networks combined with wavelet analysis," Applied Thermal Engineering, vol. 25, no. 2-3, pp. 161-172, 2005.

[6] I. Daubechies, "Orthonormal bases of compactly supported wavelets," Communication on Pure and Applied Mathematics, vol. 41, pp. 909-996, 1988

[7] Z. K. Peng and F. L. Chu, "Application of the wavelet transform in machine condition monitoring and fault diagnostics: A review with bibliography," Mechanical Systems and Signal Processing, vol. 18, pp 199-221, 2004.

[8] A. Djebala, N. Ouelaa, and N. Hamzaoui, "Detection of rolling bearing defects using discrete wavelet analysis," Meccanica, vol. 43, no. 2, pp 339-348, 2008

[9] I. Daubechies, Ten Lectures on Wavelets, 1st ed., USA, SIAM, 1992 , ch. 2, pp. 17-52

[10] Y. Jianguo, "An anti-aliasing algorithm for discrete wavelet transform," Mechanical Systems and Signal Processing, vol. 17, no. 5, pp. 945-954, 2003.

[11] S. Mallat, A Wavelet Tour of Signal Processing, 1st ed., USA, Academic Press, Boston, 1998, ch. 8, pp. 322-374

[12] N. Lu, F. Wang, and F. Gao, "Combination method of principal component and wavelet analysis for multivariate process monitoring and fault diagnosis," Ind. Eng. Chem. Res, vol. 42, pp. 4198-4207, 2003. 
[13] S. G. Mallat, "A theory for multi-resolution signal decomposition: the wavelet representation," IEEE Trans Pattern Anal Machine Intelligence, vol. 11, no. 7, pp. 674-693, 1989.

[14] D. E. Newland, "Wavelet analysis of vibration, part I: theory, part II: wavelet maps," Journal of Vibration and Acoustics, vol. 116, pp. 409-416, 1994

[15] D. E. Newland, "Wavelet analysis of vibration, part I: theory, part II: wavelet maps," Journal of Vibration and Acoustics, vol. 116, pp. $417-425,1994$

[16] A. Akers and S. J. Lin, "Optimal control theory applied to a pump with single-stage electro-hydraulic servo valve, "ASME Journal of Dynamic System, Measurement, and Control, vol. 110, no. 2, pp. 120-125, 1988.

[17] A. Akers and S. J. Lin, "Optimal control theory applied to pressure-controlled axial piston pump design," ASME Journal of Dynamic Systems, Measurement, and Control, vol. 112, no. 3, pp. 475-481, 1990

[18] B. Lamitto, A. Jansson, and J.-O. Palmberg, "A new concept of computer controlled electro-hydraulic system: The PQ pump combined pump and valve control," presented at Second Bath International Fluid Power Workshop - fluid Power Components and Systems, 1989.

[19] N. D. Manring and R. Johnson, "Modeling and designing a variable displacement open-loop pump," ASME Journal of Dynamic Systems, Measurement, vol. 118, 1996.

[20] N. D. Manring and G. R. Lueche, "Modeling and designing a hydraulic transmission with a fixed-displacement motor," ASME Journal of Dynamic System, Measurement, and Control, vol. 120, no. 1, pp. 4549 , 1998.

[21] N. D. Manring and H. Du, "An Adaptive Pressure servo control design for variable displacement pumps," in Proc. the ASME International Mechanical Engineering Congress and Exposition, 2000, vol. 96, no. 1, pp. 305-312.

[22] N. D. Manring, "The control and containment forces on the swash plate of an axial piston pump," ASME Journal of Dynamic Systems, Measurement, and Control, vol. 121, no. 4, pp.77-86, 1999

[23] M. K. B. Khalil, V. Yurkevich, J. Svoboda, and R. B. Bhat, "Implementation of single feedback control loop for constant power regulated swash plate axial piston pumps," International Journal of Fluid Power, vol. 3, no. 3, pp. 27-36, 2002

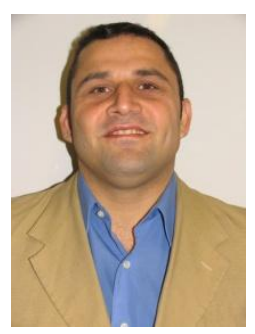

Molham Chikhalsouk is a researcher of Mechanical and Industrial Department at Concordia University, Montreal, Canada. He obtained his $\mathrm{Ph}$.D. from Concordia University and his thesis was about the design and control of hydraulic systems and also, using the systems vibration signature in monitoring their condition.

Dr. Chikhalsouk is a member of several engineering associations in North America such as American Society of mechanical engineering, Canadian Society of mechanical engineering, Canadian Acoustical Association, Canadian Aeronautics and Space Institute, and American Society for quality. He also, is a professional engineer in Ontario Engineers Order since 2003. He had several publications about the design and control of hydraulic systems.

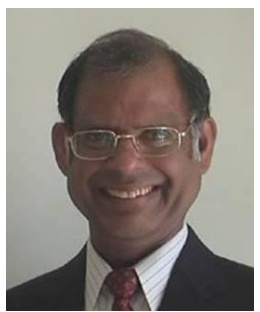

Rama B. Bhat is a professor of Mechanical and Industrial Engineering Department at Concordia University, Montreal, Canada. His research area covers mechanical vibrations, vehicle dynamics, structural acoustics, rotor dynamics, and dynamics of micro-electro-mechanical systems. He has trained many Ph.D. students in these areas since he joined the department of Mechanical and Industria Engineering in 1979.

$\mathrm{He}$ is a fellow of the Canadian Society for Mechanical Engineering, Engineering Institute of Canada, American Society of Mechanical Engineers, Institution of Engineers (India). He served as the president of Canadian Society for mechanical engineering in 2004-2006. He has been awarded the prestigious NASA Award for technical innovation for his contribution in developing "PROSSS-Programming Structured Synthesis System". Dr. Bhat is a registered professional engineer in the Province of Quebec in Canada. 